\title{
Research Paper: The Mediating Role of Automatic Thoughts in Relationship Between Attachment Style with Sexual Dysfunction and Marital Commitment: A Path Analysis
}

\author{
Nayereh Abdollahi $^{1 *}$ (D), Shadi Jazini ${ }^{1}$ (D), Khaled Aslani' ${ }^{1}$ (D), Abas Amanelahi ${ }^{1}$ (D)
}

1. Department of Counseling, Faculty of Education and Psychology, Shahid Chamran University of Ahvaz, Ahvaz, Iran

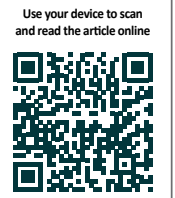

dtation Abdollahi N, Jazini Sh, Aslani Kh, Amanelahi A. The Mediating Role of Automatic Thoughts in Relationship Between Attachment Style with Sexual Dysfunction and Marital Commitment: A Path Analysis. Journal of Research \& Health. 2020; 10(2):91-102. http://dx.doi.org/10.32598/JRH.10.2.5

doi http://dx.doi.org/10.32598/JRH.10.2.5

\section{(i) (5)}

Article info:

Received: 28 Sep 2019

Accepted: 05 Jan 2020

Publish: 01 Mar 2020

\section{Keywords:}

Attachment Site, Automatic thoughts, Physiological, Marital commitment

\section{ABSTRACT}

Background: This article explores the effects of attachment style and automatic thoughts on sexual dysfunction and marital commitment, using the path analysis model. This descriptivecorrelational study was conducted on 375 married female students in Shahid Chamran University of Ahvaz, Iran, from 2016 to 2017.

Methods: According to Morgan and Jersey table and the statistical population (375 people), the number of samples was calculated as 180 . Female sexual function index, marital commitment questionnaire, behavioral systems questionnaire, and sexual modes inventory were used for data collection. Then, the obtained data were analyzed with the path analysis.

Results: The results indicated that: 1 . secure and insecure attachment styles had no direct effects on the sexual dysfunction, although they were significantly related to the automatic thoughts; 2. secure and insecure attachment styles had a direct impact on the marital commitment; 3 . automatic thoughts were a mediating variable; 4 . automatic thoughts were positively related to the sexual dysfunction and negatively related to the marital commitment. Based on the findings of this research, the relationship between attachment styles and automatic thoughts were predictors of sexual dysfunction and marital commitment.

Conclusion: Sexual function and commitment to marital relationships among couples can be increased by correcting automatic thoughts and providing necessary training about the attachment styles for parents.

\footnotetext{
* Corresponding Author:

Nayereh Abdollahi, $P h D$.

Address: Department of Counseling, Faculty of Education and Psychology, Shahid Chamran University of Ahvaz, Ahvaz, Iran.

Phone: +98 (917) 6746598

E-mail:abdollahi311@yahoo.com
} 


\section{Introduction}

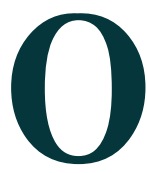

$\mathrm{n}$ the verge of the third millennium, family is still considered as the main pillar of society. Sexual relations partly form a couple's understanding of each other. In other words, satisfactory sexual functioning plays an essential role in improving women's health and their quality of lives [1]. Female Sexual Dysfunction (FSD) is a common disorder in all societies worldwide. It is also a complex and multifactor phenomenon that encompasses emotional intimacy and relationship satisfaction, along with other psychosocial factors across all cultures, and all sexual orientations and various socioeconomic statuses. It has great potential to affect relationships negatively and impair the quality of life [2].

Sexual dysfunction, as the main root of communicative conflicts among couples, can cast doubts and concerns about partnership interests and sustainability of the relationship [1]. In other words, the sustainability of the relationship is about having the same commitment to the relationship. Relationship commitment is characterized by a willingness or deliberate intention to continue a relationship and psychological attachment to a specific partner and relationship [3]. Marital commitment is defined when couples have long-term views about their marriage and make sacrifices for the relationship. They make every endeavor to keep and strengthen their bonds And they do not get divorced even if they have a failed marriage [4].

Maintaining a satisfying heterosexual relationship is important to the happiness and physical health of many people. Mutuality of commitment is critical to pro-relationship transformation and develops as a process of paying attention to yourself and your spouse repeatedly is a top priority in life [5]. Commitment refers to the degree to which one intends to continue a relationship indefinitely and work to preserve it [6]. Given that sexual dysfunction is an unexplored public problem and commitment plays a central role in the individual and family's wellbeing, investigating variables related to these two issues is essential.

The attachment hypothesis states that intimate relationships between a child and those close to him or her in childhood is responsible for the bond that develops between adults in emotionally intimate relationships [7]. Bowlby's theory of attachment suggests that the intimate bonds that a child forms with their caregivers make the blueprint for future relationships. The links between adult attachment and sexual dysfunction have already been well established [8]. Prior research suggests that securely-attached individuals have more positive sexual experiences in their relationships.

Feeney and Noller (1990) found that secure individuals reported greater mutual support in their relationships [7, 9]. In contrast, insecure individuals are especially vulnerable to the feeling of rejection during sexual interactions [10]. They keep trying to retain a sense of distance and lack of vulnerability in the sexual realm, due to their discomfort with intimacy and their general feeling to remain self-reliant $[9,10]$. Associations between adult attachment and commitment have been evident in recent research $[11,12]$. Secure attachment has been predictive of relationally-oriented variables such as satisfaction, commitment, and trust [11, 12]. Having the least difficulty, a secure person develops and maintains relationships. The confident person values closeness with others while not overly dependent on them. Those who possess insecure styles desire closeness with others but are afraid of being hurt, so they tend to withdraw from intimate interactions with others [13].

We define adult attachment as the stable tendency of individuals to seek and maintain proximity to and contact with one or a few special individuals who provide the subjective potential for physical and or psychological safety and security. Also, the attachment style becomes a base to explore [7, 14] four fundamental attachment styles, which vary depending on the particular combination of the ways the person and others are generally viewed. Fundamental attachment styles include secure (positive views of self and others), preoccupied (negative self and positive other views), dismissing (positive self and negative other views), and fearful (negative views of self and others) $[15,13]$. The styles are conceptualized as relatively distinct and categorical, although the last three are typically considered to fall under the general heading of insecure styles [13].

Individuals have more or less secure attachment styles in their close relationships with others as a result of their early interactions with primary caregivers since childhood [13]. Given that the secure adult attachment provides love, care, and support and allows individuals to broaden and build their capacities, the smooth functioning of the attachment system is regarded as crucial for maintaining satisfying relationships [16]. Compared with securely-attached people, insecurely-attached individuals reported more experiences of sexual behavior with strangers, and commit more acts of infidelity [1719]. Although studies have examined the relationship between attachment behavior and commitment, much less 
is known about the relation between adult attachment and sexual dysfunction [5].

Evolutionary theories on the formation of relationships suggest that adult attachment and relationship commitment are universal mechanisms for securing and maintaining such mating relationships [4]. In other words, attachment style is associated with lifetime sexual behavior. Securely-attached individuals tend to be comfortable with their sexuality, are open to sexual exploration, and enjoy a variety of sexual activities [20]. This type of attachment will increase positive sexual satisfaction, and partners will be able to clearly express their love and affection in their relationships [21]. Some insecure individuals experience aversive feelings and intrusive thoughts with regard to sex, prefer to distance themselves from intimate sexual activities and experience lower levels of sexual intimacy and pleasure-related sexual feelings [22]. Insecure individuals might have difficulty differentiating among aspects of their sexual experiences and their relationships as a whole, which could potentially result in the relational instability if their sexual experiences are negative or unsatisfying [23].

In the present study, we found out that attachment was related not only to sexual dysfunction but also to marital commitment and automatic thoughts. Automatic thoughts are images or cognitions presented by subjects as the result of the cognitive schema or core beliefs, activated in a particular moment; thus, automatic thoughts reflect the content of the more central and tacit structures of the cognitive system. These images and thoughts reflect the meaning that subjects assign to a given situation and are deeply associated with the emotional and behavioral responses to that event. Moreover, automatic thoughts play an essential role in the therapeutic process, being used as a preferential access pathway to the cognitive system and help understand the core beliefs underlying several psychological disorders [24].

Men and women with sexual dysfunctions reported significantly more negative thoughts during the sexual activity compared with the sexually-healthy individuals, failure and disengaged thoughts (I'm not satisfying my partner, I'm not getting turned on, when will this be over?), sexual abuse thoughts (this is disgusting, he only wants to satisfy himself), and lack of erotic thoughts were significantly more common in women with sexual dysfunction compared with sexually-healthy women [25]. A typical model of sexual dysfunction consists of negative automatic thoughts, depressive affects, and low subjective sexual arousals [26].

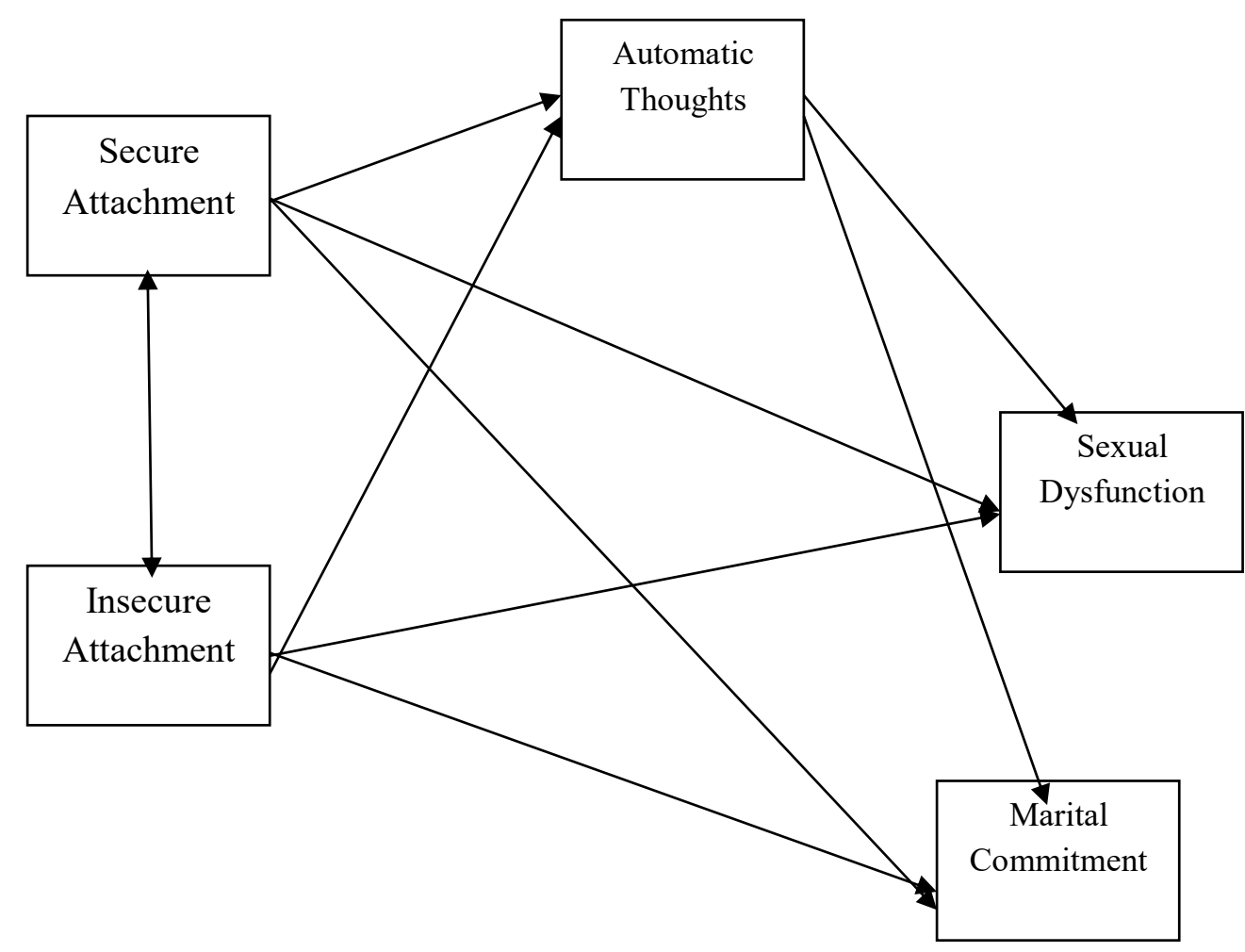

Figure 1. The proposed mediation model of automatic thoughts in the relationship between attachment styles to sexual dysfunction and marital commitment 
Since Iranian researchers have rarely dealt with sexual problems and disabilities and their effects on the amount of people's commitment in society, especially among women, our primary goal was to explore and predict factors that were previously found as predictors of this problem in other societies. Therefore, the main motive of this study was to see if the factors underlying sexual disability and betrayal in Western cultures are the predictors of this disorder and problem in Iran, too. As previously mentioned, the main goal of this study was to gain a clear understanding of the way attachment styles affect automatic thoughts and the way they simultaneously affect the sexual malfunction and the level of women's commitment.

The following are the main goals of this research: to investigate the relations among attachment style, automatic thoughts, sexual dysfunction, and marital commitment in a single path model.

\section{Methods}

\section{Study Participants}

This descriptive-correlational study was conducted on the statistical population of 375 married female students in Shahid Chamran University of Ahvaz, Iran, from 2016 to 2017 academic year. The study participants were 180 married female students of this University. The inclusion criteria were being between 18 and 35 years old, being married, and finally being student, engaged, and resident of Ahvaz for more than a year. The exclusion criteria were not responding to more than three questions or filling out two options for one question.

The mean age of the participants was 26.79 years (SD $=5.22$ years). The duration of marriage with the current partner ranged from 1 to 20 years (Mean $=5$ years, SD $=4$ years). According to Morgan and Jersey table, the number of samples was estimated as 180. Also, according to the Cochran formula with 0.05 error, $95 \%$ confidence level, and a statistical population of 375 people, the number of the samples was calculated to be 190 . Accordingly, researchers selected 190 as a sample, and 180 analyzable questionnaires were collected.

Informed consent was obtained from the participants, and the confidentiality of their responses was assured before they filled out the questionnaire. A debriefing note was distributed to each participant after they completed the questionnaire.

\section{Study measures}

\section{Attachment style}

Adolescents' reports on the attachment style scale of the behavioral systems questionnaire (BSQ; Furman \& Wehner, 1999) were used to assess their self-perceptions of attachment styles with parents. This measure has had previously demonstrated acceptable internal reliability and validity (e.g. Furman \& Simon, 2004; Furman, Simon, Shaffer, \& Bouchey, 2002). This self-report questionnaire was a 19-item instrument and contained a series of questions about how adolescents approached attachment in parent-adolescent relationships.

For example, "I consistently turn to my parents when I am upset or worried". Continuous measures of the secure, dismissing, and preoccupied attachment styles (Cronbach $\alpha$ values $=0.75$ to 0.89 ) were each assessed with 5 items rated on a 5-point Likert-type scale. Once again, the secure and dismissing scales were strongly negatively related $(\mathrm{r}=-0.73)$. Accordingly, these scales were combined to create a dismissing-secure style scale. Higher scores reflected greater dismissing qualities; whereas, lower scores reflected more security of the attachment style [27]. The Cronbach $\alpha$ of the adolescents' reports on the attachment style scale was calculated in Iran, and the value 0.71 for secure attachment style and value 0.85 for insecure attachment style indicated the questionnaire's suitable reliability [28].

\section{Sexual Modes Questionnaire}

The Sexual Modes Questionnaire (SMQ; Nobre \& Pinto-Gouveia, 2003) is a measure that assesses automatic thoughts, emotions, and sexual responses during sexual activity. The questionnaire involves an Automatic Thought (AT) subscale, assessing the Emotional Response (ER), and Sexual Response ratings (SR) to the automatic thought items. The AT has a male and a female version. The male version consists of 30 items and the female version consists of 33 items evaluating the automatic thoughts and images presented during the sexual activity. The participants rated the frequency in which they experienced the automatic thoughts during the sexual activity on a response scale ranging from 1 (never) to 5 (always). Psychometric studies support the reliability and validity of the subscales [29].

Test-retest data indicated a statistically significant correlation $(\mathrm{r}=0.99, \mathrm{P}<0.05)$ for the total scale between two consecutive administrations (with a 2 -week interval) of the female version $(n=23)$, and a moderate correlation 
$(\mathrm{r}=0.65, \mathrm{P}<0.05)$ for the male version (possibly due to the low sample size, $n=9$ ). The Cronbach $\alpha$ of 0.88 for the male and 0.87 for the female version supported the internal consistency of both scales. Convergent validity indicated that the AT subscale was strongly associated with the measures of sexual functioning. The female version was significantly correlated with the Female Sexual Function Index $(\mathrm{FSFI})(\mathrm{r}=0.49, \mathrm{P}<0.01)$ and the male version with the International Index Of Erectile Function (IIEF) $(\mathrm{r}=0.60, \mathrm{P}<0.05)$ [29]. The Cronbach $\alpha$ value of the SMQ was calculated by Jazini (2017) in Iran, and the value 0.77 indicates the questionnaire's suitable reliability [30].

\section{Sexual dysfunction}

The Female Sexual Function Index (FSFI) (Rosen et al., 2000) is a 19-item instrument, providing information on the major dimensions of the sexual function. A principal component analysis identified six factors: sexual interest/desire, sexual arousal, lubrication, orgasm, sexual satisfaction, and sexual pain. The measure has acceptable test-retest reliability $(\mathrm{r}=0.79-0.86)$, internal consistency (Cronbach $\alpha \geq 0.82$ ), and discriminant validity. The measure allows the calculation of specific indexes for each dimension as well as the sexual function index (calculated through the sum of the specific dimensional indexes), with higher scores indicating greater levels of sexual functioning (desire, 1.2-6; arousal, 0-6; lubrication, 0-6; orgasm, 0-6; global satisfaction, 0.8-6; pain, $0-6$; total, 2-36) [31]. The Cronbach $\alpha$ of FSFI was calculated in Iran as 0.88 , indicating the questionnaire's suitable reliability [32].

\section{Marital commitment}

The commitment scale is a 43-item self-report measure that assesses the levels of personal commitment, moral commitment, and structural commitment. Various subscales measure each component. Subscales of personal commitment include attraction to the partner, attraction to the relationship and the couple's identity. Subscales of moral commitment include consistency values, and subscale of structural commitment include alternative, social pressures, and investments. Sample items are "To what extent do you love your partner at this stage?" (personal commitment), "I could never leave my partner because he/she needs me too much" (moral commitment), and "I would lose all the time I had put into the relationship" (structural commitment). Participants respond to the items on a 5-point Likert scale, ranging from $1=$ "strongly disagree" to 5= "strongly agree".

Evidence for the reliability of the three dimensions of the commitment was provided by subjecting 18 items to a principal-components analysis in a sample of 187 married individuals. Significant correlations supported the test validity in expected directions with other commitment measures and relationship variables, such as marital interaction and life satisfaction [33]. The Cronbach $\alpha$ of the marital commitment scale was calculated in Iran as 0.86 , indicating the questionnaire's suitable reliability [34].

Moreover, the data were analyzed using the path analysis, and indirect effects analysis of the research variables was done using the bootstrap macro.

\section{Results}

We conducted univariate and bivariate analyses to examine the distributional properties of the measures and the linear relations among variables. Table 1 shows the frequency of age and marriage duration in married female students chosen from Shahid Chamran University of Ahvaz in 2016-2017.

Table 1. Frequency of age and marriage duration among the studies population

\begin{tabular}{|c|c|c|c|}
\hline Age (y) & No. & Marriage Duration (y) & No. \\
\hline $18-20$ & 18 & $1-4$ & 100 \\
\hline $21-23$ & 41 & $5-8$ & 38 \\
\hline $24-26$ & 38 & $9-12$ & 21 \\
\hline $27-29$ & 25 & $13-16$ & 12 \\
\hline $30-32$ & 16 & $17-20$ & 6 \\
\hline $33-35$ & 39 & & \\
\hline
\end{tabular}


Table 2. The Pearson correlation coefficients

\begin{tabular}{|c|c|c|c|c|c|}
\hline Correlation & 1 & 2 & 3 & 4 & 5 \\
\hline 1. Automatic thoughts & - & & & & \\
\hline 2. Sexual dysfunction & $0.63^{*}$ & _- & & & \\
\hline 3. Marital commitment & $-0.57^{*}$ & $-0.46^{*}$ & _ & & \\
\hline 4. Secure attachment & $-0.42^{*}$ & $-0.35 *$ & $0.68^{*}$ & - & \\
\hline 5. Insecure attachment & $0.56^{*}$ & $0.39 *$ & $0.62 *$ & $0.30 *$ & _- \\
\hline Mean $\pm S D$ & $60.74 \pm 0.16$ & $23.48 \pm 11.56$ & $165.79 \pm 27.15$ & $31.25 \pm 6.88$ & $50.24 \pm 14.88$ \\
\hline
\end{tabular}

${ }^{*} \mathrm{P}=0.01$ (two-tailed)

MPA

Table 2 shows the estimated values the Pearson correlation coefficients, means, and standard deviations. We conducted a correlation analysis using path analysis. In this analysis, the relationships among the variables are estimated concurrently in a single equation, and several outcomes can be predicted at the same time. Path analysis uses only observed variables (represented as rectangles).

The four assumptions of the path analysis were investigated before analyzing the data related to hypotheses, to make sure that the data meet the underlying assumptions of the path analysis model, including missing data, checking outliers, normality, and multicollinearity.

In the present study and for dealing with missing data, we used a data substitution method with the variable mean. Furthermore, the Z-scores of variables were calculated using SPSS to examine single-variable outliers. The results showed that scores of all variables were within 2SD above or below the mean. In the present study, the skewness and kurtosis of variables were used to examine the normality of variables. Table 3 shows the results of testing the normality of studied variables.
As shown in Table 3, skewness and kurtosis coefficients for the secure attachment variable were -0.699 and -0.098 , for the insecure attachment variable 0.665 and 0.011 , for the variable of automatic thoughts 0.471 and -0.652 , the sexual dysfunction 0.087 and -0.749 , and the marital commitment -0.418 and -0.792 ; respectively. Tables 3 and 4 show that with respect to the criterion of normality, all of the research variables had the absolute value of the skewness coefficient smaller than 3 and the absolute value of the kurtosis coefficient lower than 10 , and thus the violation of the data normality was not observed.

In the present study, the multicollinearity of the variables was investigated using the tolerance statistic and Variance Inflation Factor (VIF). Table 4 reports the results of examining multicollinearity.

According to Table 4, the obtained tolerance values for variables are higher than 0.10 , indicating the absence of multicollinearity among variables. Moreover, the amount of the inflation variance obtained for variables was less than 10 , revealing no multicollinearity among variables.

Table 3. The columns of the table must be reversed

\begin{tabular}{ccccc}
\hline Indices & Skewness & $\begin{array}{c}\text { Skewness Standard } \\
\text { Deviation }\end{array}$ & Kurtosis & $\begin{array}{c}\text { Kurtosis Standard } \\
\text { Deviation }\end{array}$ \\
\hline Securiables & -0.699 & 0.183 & -0.098 & 0.363 \\
\hline Insecure attachment & 0.665 & 0.183 & 0.011 & 0.363 \\
\hline Automatic thoughts & 0.471 & 0.183 & -0.652 & 0.363 \\
\hline Sexual dysfunction & 0.087 & 0.183 & -0.749 & 0.363 \\
\hline Marital commitment & -0.418 & 0.183 & -0.792 & 0.363 \\
\hline
\end{tabular}


Table 4. The columns of the Table must be reversed

\begin{tabular}{ccc}
\hline \multicolumn{1}{l|}{ Variable } & Tolerance Statistic & Variance Inflation Factor \\
\hline Secure attachment & 0.816 & 1.125 \\
Insecure attachment & 0.681 & 1.468 \\
Automatic thoughts & 0.614 & 1.629 \\
\hline
\end{tabular}

We used Amos statistical 22 program to fit the path model that we hypothesized. We attenuated each observed variable's variance by removing its error variance; attenuation allowed us to examine the true relations among our observed variables. Figure 1 represented our complete model. AMOS allows regression coefficients to be estimated for the effects of the independent variable (e.g. attachment style) on the dependent variable (e.g. marital commitment). To determine whether the automatic thoughts mediated the link between insecure and secure attachments to the sexual dysfunction and marital commitment, we examined the significance of the indirect path from insecure and secure attachments to the sexual dysfunction and marital commitment. To examine our present hypotheses, we used bootstrapping analysis with macro developed by Preacher and Hayes (2004). Bootstrapping analysis (5000 bootstrap samples with $95 \%$ confidence interval) has the advantage of not assuming the normality of the sampling distribution, making it appropriate for small samples [35].
The baseline model (Model 1) with no constraints demonstrated a satisfactory fit to the data, with $\mathrm{X} 2 / 1=1.78$, $\mathrm{P}=0.181$, Goodness of Fit Index $(\mathrm{GFI})=0.99$, Normed Fit Index $(\mathrm{NFI})=0.99$, incremental fit index $(\mathrm{IFI})=0.99$, Comparative Fit Index $(\mathrm{CFI})=0.99$, the Root Mean Square Error of Approximation $($ RMSEA) $=0.06$, which indicates that our model fit the data.

In particular, we found that sexual dysfunction was not related to the secure and insecure attachments. Moreover, sexual dysfunction was positively associated with automatic thoughts, but marital commitment positively associated with secure attachment and negatively related to insecure attachment and automatic thoughts. Thus, further analysis was needed to examine and modify the basic model and the significance of the indirect paths leading from insecure and secure attachments to sexual dysfunction and marital commitment through automatic thoughts. Figure 2 shows the final, modified model

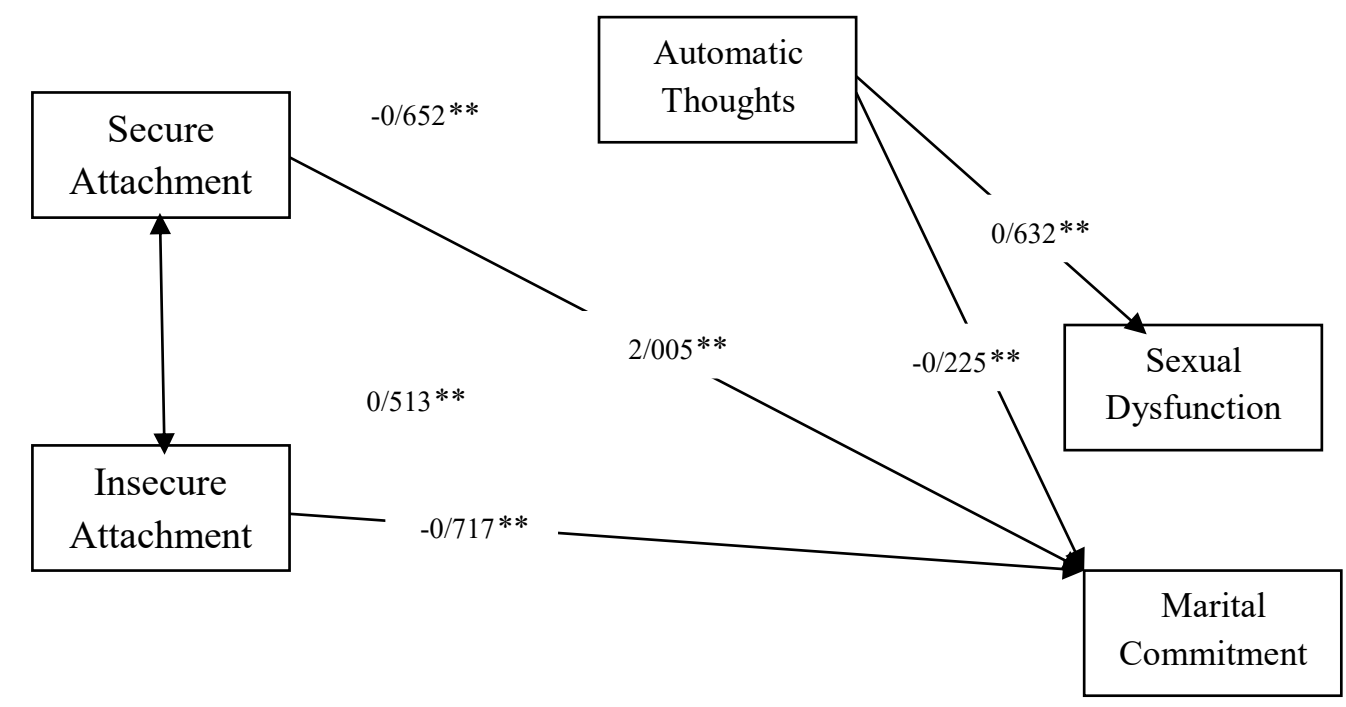

Figure 2. Model coefficients and direct and indirect effects of the research variables

**P=0.01 (two-tailed) 
Table 5. Bootstrap methods to test the significance of mediation effects

\begin{tabular}{|c|c|c|c|c|c|c|}
\hline \multirow{2}{*}{$\begin{array}{l}\text { Indirect paths } \\
\mathrm{S} \rightarrow \mathrm{Au} \longrightarrow \mathrm{Sex}\end{array}$} & \multirow{2}{*}{$\begin{array}{c}\text { Boot } \\
-0.4211\end{array}$} & \multirow{2}{*}{$\begin{array}{c}\text { SE } \\
0.0726\end{array}$} & \multirow{2}{*}{$\begin{array}{c}\text { Bias } \\
-0.0020\end{array}$} & \multirow{2}{*}{$\begin{array}{c}\mathbf{P} \\
0.0000\end{array}$} & \multicolumn{2}{|c|}{$\begin{array}{l}\text { Bootstrap with bias } \\
\text { correction }\end{array}$} \\
\hline & & & & & -0.5757 & -0.3014 \\
\hline 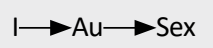 & 0.2653 & 0.0408 & 0.0028 & 0.0000 & 0.1889 & 0.3523 \\
\hline $\mathrm{S} \rightarrow \mathrm{Au} \longrightarrow \mathrm{Ma}$ & 0.5715 & 0.1294 & 0.0039 & 0.0000 & 0.3410 & 0.8453 \\
\hline $\mathrm{I} \longrightarrow \mathrm{Au} \longrightarrow \mathrm{Ma}$ & 0.3254 & 0.0829 & 0.0042 & 0.0000 & -0.1561 & -0.1828 \\
\hline
\end{tabular}

In:

S: Secure Attachment; Au: Automatic Thoughts; Sex: Sexual dysfunction; I: Insecure attachment; Ma: Marital commitment

The modified model (Model 2) demonstrated a satisfactory fit to the data, with $\mathrm{X} 2 / 3=1.49, \mathrm{P}=0.213$, GFI $=0.99$, $\mathrm{NFI}=0.99$, IFI $=0.99, \mathrm{CFI}=0.99$, and $\mathrm{RMSEA}=0.05$.

We conducted a bootstrapping analysis with macro to examine the significance of the indirect paths depicted in the model, testing the hypothesis of no difference between the total effect and the direct effect. This procedure determines the significance of the mediator by examining whether the indirect path from the independent variable (i.e. attachment styles) to the dependent variable (i.e. relationship satisfaction) is significantly different from zero. Results of path analyses using the bootstrapping analysis with macro indicated that automatic thoughts mediated the link between insecure and secure attachments to sexual dysfunction and marital commitment.

As shown in Figure 2, no path has been eliminated in the model because of the significance of all the model coefficients is at 0.05 level. Generally, the coefficients $\leq 0.01$ are not significant in the model, and, as we see, all coefficients are above 0.01 .

\section{Discussion}

Our findings supported the mediation model of automatic thoughts, so the pathways between attachment styles to sexual dysfunction and marital commitment are significant.

The secure form of the attachment is a normative feature of the human species in regulating close relationships. Moreover, attachment as the bonding that promotes favorable relationship outcomes seems to be a universal phenomenon [4]. Hence, it is not surprising to find support for hypothesis 1 , such that attachment orientation is found to be intrinsically associated with dys- functional communication patterns regarding sexual issues and concerns [36]. Previous studies have indicated that higher levels of insecure attachment were associated with a higher incidence of sexual problems in women [8]. In other words, the insecure attachment was related to aversive sexual affections and cognition [22] that gradually led to sexual dysfunction while secure individuals exhibit a higher frequency of sexual intercourse and reported more enjoyment from sex than their less secure counterparts [37].

The results of the current study about hypothesis 2 also supported previous studies' outcomes [4, 12, 22], suggesting that secure attachment is related to relationship satisfaction. It makes sense that the more securelyattached people in their relationships, feel more pleasure. Securely-attached individuals are more comfortable getting close and intimate with their partners, and they can trust them more. The romantic relationship of securely attached couples will be more emotionally stable, more tolerant of differences, less confusing, more two-sided and reciprocal, and more intimate due to the larger amount of trust [38].

All of these aspects of secure relationships will lead to more marital commitment. However, people with insecure attachment styles have low commitments in their marital relationships. People who have insecure attachment styles are those who have doubts about their values in their internal activation patterns and they have positive evaluations of others (their spouses); they are constantly looking to bolster their assurance and blame themselves for their relationship problems. Most importantly, these people usually consider any behavior of their spouses as a sign of abandonment, and this characteristic hinders them from committing to their spouses [25]. 
The results from the current study also supported hypothesis 3 . The findings supported the need to focus on psychological factors in women's experience of sex. In women with sexual dysfunction, we expect to find higher sexual abuse thoughts, failure and disengagement thoughts, partners' lack of affection, passivity and control thoughts, and low self-body image thoughts. In other words, results indicated that men and women with sexual dysfunction reported significantly more negative thoughts during sexual activity compared with sexually healthy individuals [25].

In contrast, the marital commitment was negatively associated with automatic thoughts. Thus, the current study also supported hypothesis 4 . Overall, our results support the existence of a typical underlying thought pattern in women with low commitment. Women with low commitment reported a lack of erotic thoughts during sexual activity. Besides, they had disengagement thoughts. On the other hand, age and body-related thoughts and negative thoughts towards sexuality certainly help distinguish women with low commitment. In other words, it was found that women who were more satisfied with their marital relationships and perceived it as more intimate, were less concerned with their body images. These results suggest that a more positive couple relationship can be one of the factors that help women feel more comfortable with their bodies and less concerned with their body images, which, in turn, is associated with the more positive subjective perception of the married life, and more positive feelings [39].

Furthermore, the findings of the current study support hypothesis 5, confirming that automatic thoughts significantly mediate the pathway from attachment styles to sexual dysfunction. Insecure individuals tend to have relatively unstable and unsatisfying relationships due to their emotional distance, fear of intimacy, and low levels of trust $[23,36]$. They tend to find sexual relationships unrewarding and uncomfortable, due to their general discomfort with closeness and intimacy and are inclined to find their sexual relationships less satisfying. In contrast, some individuals' insecure fear of losing the partner might bring anxiously attached women to focus on the satisfaction of their partner's needs to the point that they forget to pay attention to their sexual sensations [36].

Moreover, insecure adults reported more automatic thoughts compared with secure ones. On the other hand, previous research [25] showed that men and women with sexual dysfunction had more negative thoughts during sexual activity compared with sexually-healthy individuals. Failure and disengagement thoughts (I'm not satisfying my partner, I'm not getting turned on, when will this be over?), sexual abuse thoughts (this is disgusting, he only wants to satisfy himself), and lack of erotic thoughts were significantly more common in women with sexual dysfunction compared with the sexually-healthy women [26]. Individuals with a secure attachment style tend to develop a strong sense of self and view others as reliable and trustworthy. They are found more likely to have intimate, satisfying, and faithful long-term relationships [37, 40], with more positive views of sexuality and high levels of sexual esteem [40]. Besides, secure adults reported low automatic thoughts and more healthy sexual functions.

Another implication of these results is the confirmation of that hypothesis 6, i.e. "attachment styles affect marital commitment through automatic thoughts". Associations between adult attachment and commitment have been evident in recent research studies. Birnie et al. (2009) found that insecure attachment was associated with commitment aversion. Insecure individuals tend to reject intimacy or closeness, protect themselves from disappointments and rejection by others, and maintain a sense of independence and invulnerability. In contrast, some insecure individuals tend to search for self-acceptance through approval and acceptance by their partners, monitor their partners in a hyper-vigilant manner, cling to their partners, and obsess anxiously about potential disapproval or rejection by their partners [39]. As mentioned, negative thoughts towards sexuality certainly contribute to distinguishing women with low commitment. Thus, insecure individuals, having more automatic thoughts, indicate lower commitment in life.

This study confirmed the importance of taking the potential mediating role of automatic thoughts into account when studying the associations between attachment styles, affecting sexual dysfunction, and marital commitment. The limitation of the current study was the homogeneity of the studied samples, which consisted of primarily the college-educated female, young adults. Second, we used a self-report method to investigate the two pathways. However, other methodologies, such as self-monitoring or diary studies, qualitative methods, longitudinal, and or direct observation in the laboratory, may provide a better evaluation of the proposed hypotheses.

\section{Conclusion}

Our findings supported the role played by the thought pattern in the dysfunctional sexual processes and low marital commitment. Based on the previous studies and the importance of commitment in family stability, and 
because a healthy sexual function is an acquirable skill, providing new learning opportunities can help couples change their destructive and ineffective behaviors and adopt efficient strategies. Thus, executive authorities can introduce such training programs as a part of premarital counseling on a large scale. Establishing private and public family counseling centers to provide training courses on sexual relationships and improve attitudes and sexual expectations to strengthen marital relationships is also recommended.

\section{Ethical Considerations}

\section{Compliance with ethical guidelines}

The study was Ethically approved (License No. $98 / 3 / 21 / 55775$ historian) and registered on November 2019 .

\section{Funding}

This research did not receive any specific grant from funding agencies in the public, commercial, or not-forprofit sectors.

\section{Authors' contributions}

All authors contributed in preparing this article.

\section{Conflict of interest}

The authors declared no conflict of interests.

\section{References}

[1] Kariman N, Sheikhan Z, Simbar M, Zahiroddin A, AkbarzadehBahgban A. Sexual dysfunction in two types of hormonal contraception: combined oral contraceptives versus depot medroxyprogesterone acetate. J Midwifery and Reprod Health. 2017; 5(1):806-13

[2] Diehl A, Silva RL, Laranjeira R. Female sexual dysfunction in patients with sub-stance-related disorders. Clin. 2013; 68(2):205-12. [DOI:10.6061/clinics/2013(02)OA14]

[3] Adams JM, Jones WH. The conceptualization of marital commitment: An integrative analysis. J Pers Soc Psychol. 1997; 72(5):1177. [DOI:10.1037/0022-3514.72.5.1177]

[4] Ho MY, Chen SX, Bond MH, Hui CM, Chan C, Friedman M. Linking adult attachment styles to relationship satisfaction in Hong Kong and the United States: The mediating role of personal and structural commitment. J Happiness Stud. 2012 13(3):565-78. [DOI:10.1007/s10902-011-9279-1]

[5] Givertz M, Segrin C, Woszidlo A. Direct and indirect effects of commitment on interdependence and satisfaction in married couples. J Fam Psychol. 2016; 30(2):214. [DOI:10.1037/ fam0000174] [PMID]
[6] Ballard-Reisch DS, Weigel DJ. Communication processes in marital commitment. In: Adams JM, Jones WH, editors. Handbook of interpersonal commitment and relationship stability. New York: Springer; 1999. [DOI:10.1007/978-1-46154773-0_24]

[7] Timm TM, Keiley MK. The effects of differentiation of self, adult attachment, and sexual communication on sexual and marital satisfaction: A path analysis. J Sex Marital Ther. 2011; 37(3):206-23. [DOI:10.1080/0092623X.2011.564513] [PMID]

[8] Burri A, Schweitzer R, O'brien J. Correlates of female sexual functioning: Adult attachment and differentiation of self. J Sex Med. 2014; 11(9):2188-95. [DOI:10.1111/jsm.12561] [PMID]

[9] Mikulincer M, Shaver PR. Boosting attachment security to promote mental health, prosocial values, and inter-group tolerance. Psychol Inq. 2007; 18(3):139-56. [DOI:10.1080/10478400701512646]

[10] Brassard A, Dupuy E, Bergeron S, Shaver PR. Attachment insecurities and women's sexual function and satisfaction: The mediating roles of sexual self-esteem, sexual anxiety, and sexual assertiveness. J Sex Res. 2015; 52(1):110-9. [DOI:10.108 0/00224499.2013.838744] [PMID]

[11] Morgan HJ, Shaver PR. Attachment processes and commitment to romantic relationships. In: Adams JM, Jones WH, editors. Handbook of interpersonal commitment and relationship stability. New York: Springer; 1999 [DOI:10.1007/978-1-46154773-0_6]

[12] Tran S, Simpson JA. Prorelationship maintenance behaviors: The joint roles of attachment and commitment.: J Pers Soc Psychol. 2009; 97(4):685. [DOI:10.1037/a0016418] [PMID]

[13] Bello RS, Brandau-Brown FE, Ragsdale JD. Attachment style, marital satisfaction, commitment, and communal strength effects on relational repair message interpretation among remarrieds. Commun Q. 2008; 56(1):1-6. [DOI:10.1080/01463370701838968]

[14] Berman WH, Sperling MB. The structure and function of adult attachment. Attachment in adults: Clinical and developmental perspectives. New York: Guilford Press; 1994.

[15] Bartholomew K. Avoidance of intimacy: An attachment perspective. J Soc Pers Relat. 1990; 7(2):147-78 [DOI:10.1177/0265407590072001]

[16] Cann A, Norman MA, Welbourne JL, Calhoun LG. Attachment styles, conflict styles and humour styles: Interrelationships and associations with relationship satisfaction. Eur J Pers. 2008; 22(2):131-46. [DOI:10.1002/per.666]

[17] Bogaert AF, Sadava S. Adult attachment and sexual behavior. Pers Relatsh. 2002; 9(2):191-204. [DOI:10.1111/14756811.00012]

[18] Cooper ML, Shaver PR, Collins NL. Attachment styles, emotion regulation, and adjustment in adolescence. J Pers Soc Psychol. 1998; 74(5):1380. [DOI:10.1037/0022-3514.74.5.1380] [PMID]

[19] Gilliland R, Blue Star J, Hansen B, Carpenter B. Relationship attachment styles in a sample of hypersexual patients. J Sex Marital Ther. 2015; 41(6):581-92. [DOI:10.1080/009262 3X.2014.958787] [PMID]

[20] Butzer B, Campbell L. Adult attachment, sexual satisfaction, and relationship satisfaction: A study of married 
couples. Pers Relat. 2008; 15(1):141-54. [DOI:10.1111/j.14756811.2007.00189.x]

[21] Pinsky IS. Attachment quality and sexual satisfaction and sexual functioning in romantic relationships for combat veterans [MSc. thesis]. Lexington: University of Kentucky UKnowledge; 2016.

[22] Birnbaum GE. Attachment orientations, sexual functioning, and relationship satisfaction in a community sample of women. J Soc Pers Relat. 2007; 24(1):21-35. [DOI:10.1177/0265407507072576]

[23] Birnbaum GE, Reis HT, Mikulincer M, Gillath O, Orpaz A When sex is more than just sex: Attachment orientations, sexual experience, and relationship quality. J Pers Soc Psychol. 2006; 91(5):929. [DOI:10.1037/0022-3514.91.5.929] [PMID]

[24] Beck J. Cognitive therapy: Basics and beyond. New York: Guilford; 1996

[25] Nobre PJ, Pinto-Gouveia J. Differences in automatic thoughts presented during sexual activity between sexually functional and dysfunctional men and women. Cognit Ther Res. 2008; 32(1):37-49. [DOI:10.1007/s10608-007-9165-7]

[26] Nobre PJ, Pinto-Gouveia J. Cognitions, emotions, and sexual response: Analysis of the relationship among automatic thoughts, emotional responses, and sexual arousal. Arch Sex Behav. 2008; 37(4):652-61. [DOI:10.1007/s10508-007-9258-0] [PMID]

[27] Shomaker LB, Furman W. Parent-adolescent relationship qualities, internal working models, and attachment styles as predictors of adolescents' interactions with friends. J Soc Pers Relat. 2009; 26(5):579-603. [DOI:10.1177/0265407509354441] [PMID] [PMCID]

[28] Abdollahi, N. The investigate relationship between attachment style and marital commitment with the mediation of differentiation of self and feeling of guilt on female married students in Ahvaz [MSc. thesis]. Ahvaz: Shahid Chamran University; 2016.

[29] Nobre PJ, Pinto-Gouveia J. Sexual modes questionnaire: Measure to assess the interaction among cognitions, emotions, and sexual response. J Sex Res . 2003; 40(4):368-82. [DOI:10.1080/00224490209552203] [PMID]

[30] Jazini, Sh. Sexual dysfunction predicted based on cognitive schemas, beliefs and automatic thoughts [MSc. thesis]. Ahvaz: Shahid Chamran of Ahvaz University; 2016.

[31] Rosen C, Brown J, Heiman S, Leiblum C, Meston R, Shabsigh D, et al. The Female Sexual Function Index (FSFI): A multidimensional self-report instrument for the assessment of female sexual function. J Sex Marital Ther. 2000; 26(2):191208. [DOI:10.1080/009262300278597] [PMID]

[32] Abdollahi N, Jazini Sh, Amanollahi A, Aslani Kh. The relationship between sexual dysfunction and self-conscious emotions. J Thought \& Behav Clin Psychol. 2017; 11(43):46-37.

[33] Johnson MP, Caughlin JP, Huston TL. The tripartite nature of marital commitment: Personal, moral, and structural reasons to stay married. J Marriage Fam. 1999:160-77. [DOI:10.2307/353891]

[34] Aslani Kh, Abdollahi N, Amanellahi A. The relationship between attachment style with marital commitment: The mediation role of self-differentiation and feeling of guilt in mar- ried female students in city of ahvaz. Journal of Counseling Research. 2017; 61(16):191-220.

[35] Shrout PE, Bolger N. Mediation in experimental and nonexperimental studies: New procedures and recommendations. Psychological Methods. 2002; 7(4):422-45. [DOI:10.1037/1082989X.7.4.422] [PMID]

[36] Khoury CB, Findlay BM. What makes for good sex? The associations among attachment style, inhibited communication and sexual satisfaction. Journal of Relationships Research. 2014; 5:e7. [DOI:10.1017/jrr.2014.7]

[37] Dunkley CR, Dang SS, Chang SC, Gorzalka BB. Sexual functioning in young women and men: Role of attachment orientation. Journal of Sex \& Marital Therapy. 2016; 42(5):413 30. [DOI:10.1080/0092623X.2015.1061075] [PMID]

[38] Clymer SR, Ray RE, Trepper TS, Pierce KA. The relationship among romantic attachment style, conflict resolution style and sexual satisfaction. Journal of Couple \& Relationship Therapy. 2006; 5(1):71-89. [DOI:10.1300/J398v05n01_04]

[39] Moreira H, Crespo C, Paredes T, Silva S, Canavarro MC, Dattilio FM. Marital relationship, body image and psychological quality of life among breast cancer patients: The moderating role of the disease's phases. Contemporary Family Therapy. 2011; 33(2):161-78. [DOI:10.1007/s10591-011-9149-3]

[40] Mikulincer M, Shaver PR. The attachment behavioral system in adulthood: Activation, psychodynamics, and interpersonal processes. Advances in Experimental Social Psychology. 2003; 35:53-152. [DOI:10.1016/S0065-2601(03)01002-5] 
This Page Intentionally Left Blank 